\title{
Evaluation of Refractive Status and Ocular Biometric Parameters in Primary Angle Closure Disease
}

\author{
Chow Chin Loh ${ }^{\mathrm{a}, \mathrm{b}}$ Haireen Kamaruddin ${ }^{\mathrm{b}}$ Mae-Lynn Catherine Bastion ${ }^{\mathrm{a}}$ \\ Rahat Husain ${ }^{c}$ Hazlita Mohd Isad Norshamsiah Md. Din ${ }^{a}$ \\ aDepartment of Ophthalmology, Hospital Canselor Tuanku Muhriz, Universiti Kebangsaan Malaysia Medical Centre \\ (UKMMC), Cheras, Malaysia; 'bepartment of Ophthalmology, Hospital Selayang Lebuh Raya, Batu Caves, Malaysia; \\ 'Singapore National Eye Centre, Singapore, Singapore; ${ }^{\mathrm{d}}$ Gleneagles Hospital, Kuala Lumpur, Malaysia
}

\section{Keywords}

Primary angle closure $\cdot$ Ocular biometry $\cdot$ Refractive status

\begin{abstract}
Introduction: The aim of the study was to evaluate the refractive status and ocular biometric parameters in subjects with angle closure in Malaysia. Methods: This cross-sectional study was conducted on 171 primary angle closure patients (268 eyes). Visual acuity, refraction, and ocular biometry (central anterior chamber depth [ACD], axial length [AL], and lens thickness) were recorded. Vitreous cavity length $(\mathrm{VL})$ and relative lens position (RLP) were calculated. Results: A total of 92 Primary Angle Closure Suspect (PACS), 30 Primary Angle Closure (PAC), and 146 Primary Angle Closure Glaucoma (PACG) eyes were included. Chinese ethnicity formed the majority $(n=197,73.5 \%)$, followed by Malay $(n=$ $57,21.3 \%)$ and Indian ( $n=14,5.2 \%$ ). There was a significant female preponderance with a female to male ratio of 1.85 . Mean age was $65.7 \pm 7.7$ years. Mean spherical equivalent was $+0.33 \pm 1.29$ D. Approximately half $(n=137,51 \%)$ of the eyes were hyperopic (spherical power $\geq+0.5$ ), with PACG having the highest percentage of hyperopia ( $n=69,50.4 \%$ ). Myopia and emmetropia were present in 48 (17.9) and 83
\end{abstract}

(31\%) eyes, respectively. Although AL and VL in myopia patients were significantly longer than emmetropic and hyperopic eyes $(p<0.001)$, the ACD was not significantly different ( $p=0.427)$. While the RLP is smaller in myopic eyes, lens thickness was increased in hyperopic eyes. PACG was significantly higher in elderly patients compared to PACS and PAC ( $p=0.005)$. A total of $37(13.8 \%)$ eyes were blind (vision worse than $3 / 60$ ) and 19 of them (51.3\%) were female patients. Conclusion: A decrease in RLP is predictive of angle closure disease in myopic eyes, whereas increased lens thickness contributes to angle closure disease in hyperopic eyes.

c 2020 S. Karger AG, Basel

\section{Introduction}

Glaucoma has long been recognized as a leading cause of blindness. The scale of this problem will increase with future population growth and increasing life expectancy. The global prevalence of Primary Open Angle Glaucoma (POAG) is 3.05\% and that of Primary Angle Closure Glaucoma (PACG) is $0.50 \%$ [1]. There were around 60.5 million people with POAG and PACG in 2010, and this number is expected to increase to 79.6 million by 2020 karger@karger.com

www.karger.com/ore

(C) 2020 S. Karger AG, Base

Karger"
Norshamsiah Md. Din

Ophthalmology, Hospital Canselor Tuanku Muhriz

Universiti Kebangsaan Malaysia Medical Centre, Jalan Yaacob Latiff

Cheras 56000 (Malaysia)

shamsiahdr@hotmail.com 
[2]. Asians represent $47 \%$ of glaucoma patients and $87 \%$ of PACG patients are Asians, accounting for more angle closure glaucoma cases than other races [2]. PACG carries greater morbidity compared to POAG. While approximately 3 quarters of glaucoma patients $(74.0 \%)$ are open angle glaucoma, the number of blindness caused by both entities is almost equal [2].

It was estimated that approximately 8.4 million people were bilaterally blind from primary glaucoma in 2010 , and this might increase to 11.1 million by 2020 [2]. The impact of the disease is also similar in our region, whereby the National Eye Survey II in Malaysia (2014) has shown an estimated $1.2 \%$ prevalence of blindness in those aged 50 and above [3], and $6.6 \%$ of them from glaucoma.

There are various reports describing biometric risk factors for PACG, which include hyperopia, short axial length (AL), shallow anterior chamber depth (ACD), and increased lens thickness [4-7]. Similar biometry risk factors also predispose patients to develop an acute angle closure attack [8]. However, there are contradicting reports that short AL is not a predisposing factor for acute angle closure [5]. Other general risk factors for angle closure glaucoma (ACG) including female gender and Chinese ethnicity have also been reported [4].

The occurrence of myopia is on the rise due to more prevalent modern lifestyles such as more time spent on near work, less time outdoors, and higher educational level [9]. Myopia with longer AL had a lower prevalence of iris trabecular meshwork contact [10]. However, there are multiple reports on myopia in angle closure subjects [11-13]. While the prevalence of myopia in ACG varies in different ethnicities, the incidence of myopia in angle closure patients was relatively low across the USA, ranging between 0.05 and $1.9 \%[12,14]$, as opposed to as high as $22 \%$ in Asia, with $11.7 \%$ of them having high myopia [13].

The population in Malaysia is of mixed ethnicity and little is known of the spectrum of glaucoma cases seen locally, particularly among the non-Chinese community $[15,16]$. We aimed to evaluate whether the prevalence of myopia is higher in our population of angle closure patients and whether there are any differences in ocular biometrics among patients with angle closure in Malaysia.

\section{Materials and Methods}

This is a cross-sectional study involving all primary angle closure patients attending the Ophthalmology Clinic, Hospital Selayang. The protocol of this study was reviewed and approved by Medical Research and Ethics Committee (MREC, National Medi- cal Research Register ID: 15-2322-28532) and Research Ethics Committee of University Kebangsaan Malaysia (Reference number: UKM PPI/111/8/JEP-2016-088). A signed informed consent was obtained from all patients.

Both eyes were included in the study if they fulfill the inclusion and exclusion criteria. Primary angle closure suspect (PACS) was defined as an eye with narrow angles (2 or more quadrants of iridotrabecular contact) and intraocular pressure (IOP) of $21 \mathrm{~mm} \mathrm{Hg}$ or less in the absence of glaucomatous optic neuropathy (GON) or peripheral anterior synechiae (PAS). Primary angle closure (PAC) was defined as the presence of narrow angles with PAS and/or raised IOP of $>21 \mathrm{~mm} \mathrm{Hg}$, or both, but without GON. PACG was defined as eyes with PAC associated with GON; PAS and raised IOP may be absent at the time of initial examinations [17]. All patients had visual field examination done using a Humphrey visual field analyzer, unless the BCVA was poorer than $6 / 60$, which does not allow a meaningful visual field assessment.

Eyes were excluded if they are pseudophakic or have other types of secondary angle closure such as uveitic glaucoma or neovascular glaucoma. All patients had visual acuity assessment as measured by Snellen chart, slit-lamp examination, optic disc examination with a 78-D lens to assess signs of glaucomatous optic disc features such deep cupping, bayonetting, VCDR of $>0.7$ and rim notching, automated refraction using Refractometer AR-600A (Nidek, Japan), and IOP measurement with a Goldmann applanation tonometer. Gonioscopy was performed in the dark using a Goldmann 2-mirror lens at high magnification $(\times 16)$ and indentation gonioscopy with a Sussman 4-mirror lens was used to establish the presence or absence of PAS.

Central ACD, lens thickness, and AL were measured using the IOLMaster $^{\circledR} 500$ (Zeiss, Germany). Vitreous cavity length (VL) was calculated using the following formula: $\mathrm{VL}=\mathrm{AL}-\mathrm{ACD}-$ lens thickness; and relative lens position (RLP) was calculated as $10 \times$ [(ACD + 0.5 lens thickness)/AL] [18]. RLP was used as a predictor of appositional closure for narrow angle eyes. Refractive status was derived from the spherical equivalent of the subject's autorefraction. Refractive status was categorized as myopia ( $\leq-0.50 \mathrm{D})$, emmetropia $(-0.50$ to $+0.50 \mathrm{D})$, and hyperopia $(\geq 0.50 \mathrm{D})$.

Statistical analysis was performed using Statistical Package for Social Science, version 24.0 (SPSS, Inc., Chicago, IL, USA) for windows. All results are expressed as mean and standard deviation for continuous data and percentage for categorical data. $\chi^{2}$ test was used to compare proportion, and one-way ANOVA was used to compare means for continuous data in $>2$ groups. Post hoc Tukey HSD test was done to ascertain which pair of groups had a significant difference.

\section{Results}

A total of 268 eyes from 171 subjects were recruited. Eyes were divided into 92 PACS, 30 PAC, and 146 PACG. Most were of Chinese ethnicity $(n=197 ; 73.5 \%)$, followed by Malay $(n=57 ; 21.3 \%)$ and Indian $(n=14 ; 5.2 \%)$, representing the ethnicity distribution of the local population (Table 1). There was a significant female preponderance with a female to male ratio of 1.85 . The mean age was 
Table 1. Demographic characteristics of the study population

\begin{tabular}{|c|c|c|c|c|c|}
\hline & $\begin{array}{l}\text { PACS } \\
(n=92 \text { eyes, } 34.3 \%)\end{array}$ & $\begin{array}{l}\text { PAC } \\
(n=30 \text { eyes, } 11.2 \%)\end{array}$ & $\begin{array}{l}\text { PACG } \\
(n=146 \text { eyes, } 4.5 \%)\end{array}$ & $p$ value & $\begin{array}{l}\text { Overall } \\
(n=268)\end{array}$ \\
\hline Mean age (SD), years & $64.35(7.596)$ & $63.27(7.211)$ & $66.99(7.387)$ & $0.005^{\mathrm{a}}$ & $65.78(7.67)$ \\
\hline \multicolumn{6}{|l|}{ Ethnicity, $n(\%)$} \\
\hline Chinese & $68(73.9)$ & $23(76.7)$ & $106(72.6)$ & \multirow[t]{3}{*}{$0.780^{\mathrm{b}}$} & $197(73.5)$ \\
\hline Malay & $18(19.6)$ & $7(23.3)$ & $32(21.3)$ & & $57(21.3)$ \\
\hline Indian & $6(6.5)$ & $0(0)$ & $8(5.5)$ & & $14(5.2)$ \\
\hline \multicolumn{6}{|l|}{ Gender, $n(\%)$} \\
\hline Male & $23(25.0)$ & $11(36.7)$ & $60(41.1)$ & \multirow[t]{2}{*}{$0.040^{\mathrm{c}}$} & $94(35.1)$ \\
\hline Female & $69(75.0)$ & $19(63.3)$ & $86(58.9)$ & & $174(64.9)$ \\
\hline
\end{tabular}

PACS, primary angle closure suspect; PAC, primary angle closure; PACG, primary angle closure glaucoma; SD, standard deviation. a Significant pairwise comparisons: $p=0.022$ for PACS versus PACG; $p=0.035$ for PAC versus PACG (one-way ANOVA). ${ }^{\mathrm{b}}$ Fisher's exact test. ${ }^{c} \chi^{2}$ test.

Table 2. Refractive status and ocular biometry across angle closure groups

\begin{tabular}{|c|c|c|c|c|c|}
\hline & $\operatorname{PACS}(n=92)$ & $\operatorname{PAC}(n=30)$ & PACG $(n=146)$ & $p$ value* & Overall $(n=268)$ \\
\hline Mean spherical equivalent (SD), D & $+0.21(1.25)$ & $+0.83(0.97)$ & $+0.29(1.35)$ & 0.07 & $+0.33(1.29)$ \\
\hline Mean spherical equivalent (SD), D & $0.94(0.76)$ & $1.32(0.58)$ & $1.08(0.89)$ & 0.211 & $137(51.1 \%)$ \\
\hline Emmetropia, $n(\%)$ & $26(28.3)$ & $8(26.7)$ & $49(33.6)$ & 0.936 & $83(31)$ \\
\hline Mean spherical equivalent (SD), D & $-1.83(0.87)$ & $-1.75(0.18)$ & $-1.65(1.21)$ & 0.857 & $48(17.9)$ \\
\hline $\mathrm{ACD}, \mathrm{mm}$ & $2.51(0.23)$ & $2.60(0.33)$ & $2.54(0.34)$ & \multirow[t]{2}{*}{0.352} & \multirow[t]{2}{*}{$2.54( \pm 0.31)$} \\
\hline Mean (SD) range & $2.07-3.38$ & $2.08-3.14$ & $2.00-3.70$ & & \\
\hline $\mathrm{LT}, \mathrm{mm}$ & $4.74(0.42)$ & $4.60(0.49)$ & $4.69(0.39)$ & 0.14 & $4.70( \pm 0.42)$ \\
\hline $\mathrm{VL}, \mathrm{mm}$ & $15.40(0.73)$ & $15.48(0.14)$ & $15.48(0.06)$ & \multirow[t]{2}{*}{0.75} & \multirow[t]{2}{*}{$12.45( \pm 0.76)$} \\
\hline Mean (SD) range & $13.98-16.86$ & $13.93-16.86$ & $13.96-16.90$ & & \\
\hline RLP & $2.16(0.12)$ & $2.16(0.16)$ & $2.15(0.13)$ & \multirow[t]{2}{*}{0.93} & \multirow[t]{2}{*}{$2.15( \pm 0.13)$} \\
\hline Mean $(\mathrm{SD})$ range & $1.87-2.39$ & $1.91-2.43$ & $1.92-2.42$ & & \\
\hline
\end{tabular}

ACD, anterior chamber depth; LT, lens thickness; AL, axial Length; VL, vitreous cavity length; RLP, relative lens position; SD, standard deviation; PACG, primary angle closure glaucoma; PACS, primary angle closure suspect; PAC, primary angle closure. * ANOVA.

$65.78 \pm 7.67$ years (Table 1 ) with PACG patients being statistically older than PACS and PAC group $(p=0.005)$.

The mean spherical equivalent of all subjects was +0.33 $\pm 1.29 \mathrm{D}$ (Table 2). There was no statistically significant difference in refractive status and other biometry param- eters in all 3 groups. Slightly more than half were hyperopic ( $n=137,51.1 \%)$, with PACG having the highest percentage of hyperopia (47.3\%). Emmetropia was present in a third $(n=83,31 \%)$ of angle closure eyes. Only $17.9 \%$ (48 eyes) were myopic, with $68.75 \%(n=33)$ of them hav- 
Table 3. Refractive status and biometric parameters

\begin{tabular}{|c|c|c|c|c|}
\hline & Myopia $(n=48)$ & Emmetropia $(n=83)$ & Hyperopia $(n=137)$ & $p$ value \\
\hline Mean spherical equivalent (SD), D & $-1.72(1.06)$ & $+0.31(0.55)$ & $+1.07(0.82)$ & $<0.001^{\mathrm{a}}$ \\
\hline \multicolumn{5}{|l|}{$\mathrm{ACD}, \mathrm{mm}$} \\
\hline Mean (SD) & $2.57(0.32)$ & $2.55(0.28)$ & $2.51(0.32)$ & \multirow[t]{2}{*}{0.43} \\
\hline Range & $2.00-3.70$ & $2.15-3.38$ & $2.07-3.53$ & \\
\hline \multicolumn{5}{|l|}{$\mathrm{LT}, \mathrm{mm}$} \\
\hline Mean (SD) & $4.52(0.34)$ & $4.66(0.43)$ & $4.78(0.41)$ & \multirow[t]{2}{*}{$<0.001^{\mathrm{b}}$} \\
\hline Range & $3.63-5.14$ & $3.25-5.31$ & $3.40-5.77$ & \\
\hline \multicolumn{5}{|l|}{$\mathrm{AL}, \mathrm{mm}$} \\
\hline Mean (SD) & $22.88(0.73)$ & $22.86(0.57)$ & $22.54(0.69)$ & \multirow[t]{2}{*}{$<0.001^{\mathrm{c}}$} \\
\hline Range & $21.46-24.20$ & $21.56-23.97$ & $21.39-24.00$ & \\
\hline \multicolumn{5}{|l|}{$\mathrm{VL}, \mathrm{mm}$} \\
\hline Mean (SD) & $15.76(0.76)$ & $15.64(0.72)$ & $15.23(0.73)$ & \multirow[t]{2}{*}{$<0.001^{\mathrm{d}}$} \\
\hline Range & $14.30-16.90$ & $14.20-16.88$ & $13.93-16.86$ & \\
\hline \multicolumn{5}{|l|}{ RLP } \\
\hline Mean (SD) & $2.11(0.12)$ & $2.14(0.13)$ & $2.18(0.13)$ & \multirow[t]{2}{*}{$0.004^{\mathrm{e}}$} \\
\hline Range & $1.92-2.40$ & $1.91-2.42$ & $1.87-2.43$ & \\
\hline \multicolumn{5}{|l|}{ Age (years old) } \\
\hline Mean (SD) & $64.22(7.2)$ & $66.12(7.4)$ & $65.91(7.8)$ & 0.330 \\
\hline \multicolumn{5}{|l|}{ Gender, $n(\%)$} \\
\hline Male & $19(20.2)$ & $30(31.9)$ & $45(47.9)$ & \multirow[t]{2}{*}{0.713} \\
\hline Female & $30(17.2)$ & $52(29.9)$ & $92(67.2)$ & \\
\hline \multicolumn{5}{|l|}{ Ethnicity, $n(\%)$} \\
\hline Chinese & $33(16.8)$ & $61(31.0)$ & $103(52.3)$ & \multirow[t]{2}{*}{0.553} \\
\hline Non-Chinese & $49(18.3)$ & $21(29.6)$ & $34(47.9)$ & \\
\hline
\end{tabular}

ACD, anterior chamber depth; LT, lens thickness; AL, axial length; VL, vitreous cavity length; RLP, relative lens position; SD, standard deviation. ${ }^{a}$ One-way ANOVA, significant pairwise comparison: $p<0.001$ for myopia versus hyperopia, myopia versus emmetropia, and emmetropia versus hyperopia. ${ }^{\mathrm{b}}$ One-way ANOVA, significant pairwise comparison: $p<0.001$ for myopia versus hyperopia. ${ }^{c}$ One-way ANOVA, significant pairwise comparison: $p=0.007$ for myopia versus hyperopia, $p=0.002$ emmetropia versus hyperopia. ${ }^{\mathrm{d}}$ One-way ANOVA, significant pairwise comparison: $p<0.001$ for myopia versus hyperopia and emmetropia versus hyperopia. ${ }^{\mathrm{e}}$ One-way ANOVA, significant pairwise comparison: $p=0.006$ for hyperopia versus myopia.

ing low myopia ( $\leq-0.5$ to $-2.0 \mathrm{D}), 15$ eyes $(31.25 \%)$ had moderate ( $\leq-2.0$ to $-5.0 \mathrm{D})$ myopia, and none of our patients was highly myopic.

Table 3 shows biometric characteristic between eyes with different refractive status. There were 48 myopic eyes $(17.9 \%), 69.4 \%(n=34)$ of them had low myopia $(\leq-0.5$ to $-2.0 \mathrm{D}), 15(30.6 \%)$ eyes had moderate ( $\leq-2.0$ to -5.0 D) myopia, and none of the eyes had high myopia. All hyperope eyes are low hyperopia. The mean spherical equivalent was significantly lower in myopia group compared to emmetropia and hyperopia group $(p<0.001)$. While there was no significant difference in ACD between different groups of angle closure eyes as well as different refractive status, we found significantly longer AL and VL in the myopia group compared to the others as expected. We postulate that the ACD is not dependent on the AL but dependent on the position of the lens (RLP). To con- firm this, we analyzed the correlation between ACD, RLP, and $\mathrm{AL}$ in groups of angle closure and found that there is a rather strong correlation between ACD and RLP with a Pearson correlation coefficient of $0.62, p<0.01$, and a significantly weak correlation between ACD and AL (Pearson correlation coefficient of $0.245, p<0.01$ ).

The RLP in hyperopia group is statistically greater than the myopia group $(p=0.006)$, indicating a more anteriorly placed lens in the myopia group (Table 3 ). On the other hand, the lens thickness is significantly thicker in the hyperope group. Although the lens position is not placed more anteriorly (greater RLP), hyperopes eyes have thicker lens compared to myopes, after adjusting for age, gender, refractive status, and RLP (regression coefficient $=0.46, p<0.001)$ and that may be the risk factor for them to develop acute angle closure. 
Table 4. Vision among ethnicity and gender

\begin{tabular}{llllll}
\hline & $\begin{array}{l}\text { Good vision } \\
(n=85)\end{array}$ & $\begin{array}{l}\text { Mild visual impairment } \\
(n=99)\end{array}$ & $\begin{array}{l}\text { Moderate to severe visual } \\
\text { impairment }(n=47)\end{array}$ & $\begin{array}{l}\text { Blind } \\
(n=37)\end{array}$ & $p$ value \\
\hline $\begin{array}{l}\text { Ethnicity, } n(\%) \\
\text { Chinese }\end{array}$ & $67(25)$ & $73(27.2)$ & $34(12.7)$ & $23(8.6)$ & 0.294 \\
$\quad \begin{array}{l}\text { Non-Chinese } \\
\text { Gender, } n(\%)\end{array}$ & $18(6.7)$ & $26(9.7)$ & $13(4.9)$ & $14(5.2)$ & $18(6.7)$ \\
$\quad \begin{array}{l}\text { Male } \\
\text { Female }\end{array}$ & $32(11.9)$ & $43(16.0)$ & $1(0.4)$ & $19(7.1)$ & \\
\hline
\end{tabular}

Approximately two-thirds ( $n=184,68.7 \%)$ of eyes had at least good-to-mild visual impairment (6/12-6/18), 47 (17.5\%) had moderate to severe impaired visual acuity $(6 / 18-3 / 60)$ and $37(13.8 \%)$ were legally blind (vision worse than $3 / 60$ ). There were also more female patients suffering from the disease across diagnoses, $p<0.005$ (Table 4$)$.

\section{Discussion}

Glaucoma is the second leading cause of blindness worldwide [18]. Although POAG is the predominant glaucoma subtype, ACG carries greater morbidity, with equal proportion of blindness in both diseases [2]. Ocular biometry in PAC patients has been extensively studied, but data looking specifically into myopia and angle closure are still lacking.

The Global Prevalence of Myopia and High Myopia study predicted that by 2050 there would be 4,758 million people with myopia (49.8\% of the world population) and 938 million people with high myopia ( $9.8 \%$ of the world population) [19]. The actual rates are higher among Asian teenagers at 53\% in 2004 [20] and 38.9\% in those aged 40 years and older [20].

Much similar to other studies [13, 21, 22], slightly more than half of our patients were hyperopes, while emmetropia accounted for a third of the patients. The proportion of myopic eyes in our population is rather similar to that reported by Yong et al. [13] but lower than the 30\% reported by Liu et al. [10]. Earlier studies reported lower numbers of myopes in angle closure patients, between 1.86 and $5.5 \%$, perhaps attributed by the fact that these studies are done in the western countries. It is also possible that with increasing prevalence of myopia, especially in Asian countries, the incidence of myopia associated with angle closure also increases. In contrast to previous studies, none of our patient's eyes were highly myopic $[12,13,21]$.

We found that myopic eyes in our study population have a more anteriorly placed lens although they have a higher AL. On the other hand, hyperopic eyes have thicker lenses although the lens position is slightly posterior than myope eyes. Therefore, we could postulate that myope eyes develop angle closure because of an anteriorly placed lens, whereas hyperope eyes develop angle closure because of a thicker lens. So even when myopes have higher AL, the reason they develop angle closure is because of a more anteriorly placed lens, perhaps from zonular laxity [23]. RLP was originally introduced to address the effect of the lens on the anterior chamber. In normal eyes, lens thickness is inversely, and lens position is directly correlated with the AL [24]. Compared with eyes of average length, short eyes tend to have thicker lenses positioned more anteriorly, while long eyes tend to have thinner lenses positioned more posteriorly [6]. However, in primary angle closure disease eyes, there is a loss of co-ordination between the lens and AL. The lens is excessively thick and anteriorly placed, producing shallow anterior chambers $[6,21,25]$.

The fact that there is no statistically significant difference in the $\operatorname{ACD}(p=0.427)$ among refractive status groups further suggests that the characteristics of the anterior segment may be crowded in myopes similar to those of hyperopes and emmetropes. Furthermore, myopic eyes in our study also have more anteriorly placed lens, thereby predisposing them to get PAC [17]. This is different from a study by Yong et al. [13] done in Singapore, where they showed no difference of RLP in their myopia group.

The AL in our myopic eyes ranged between 21.46 and $24.20 \mathrm{~mm}$, suggesting a lenticular rather than axial myo- 
pia. This range of AL falls in the ranges reported by other studies in Singapore (AL range 21.33-27.48 mm in highly myopic eyes, range: -5 to $-11.88 \mathrm{D}$ ) and China (AL range $21.58-26.20 \mathrm{~mm}$ in myopic eyes, range: -0.50 to $-6.75 \mathrm{D})$, suggesting lenticular myopia as part of the causes of their myopias $[10,13]$. Unfortunately, both studies did not grade their cataract status in their analysis.

The anterior chamber characteristics such as lens vault, angle opening distance, trabeculo-iris space area, and anterior chamber angle measured with the Anterior segment Optical Coherence Tomography (AS-OCT) are some other parameters used to assess the angles in angle closure patients to explain the dynamics of such disease particularly in myopic eyes $[26,27]$. Because of the nonavailability of this machine, we could not include these parameters in our study. The grading of the cataractous lens should also be included to ascertain the state of lenticular myopia in these patients to differentiate from axial myopia, although lens thickness contributes more to the state of the ACD.

\section{Conclusion}

In conclusion, a decrease in RLP is predictive of angle closure disease in myopic eyes, whereas increased lens thickness contributes to angle closure disease in hyperopic eyes.

\section{Statement of Ethics}

The protocol of this study was reviewed and approved by Medical Research and Ethics Committee (MREC, National Medical Research Register ID: 15-2322-28532) and Research Ethics Committee of University Kebangsaan Malaysia (reference number: UKM PPI/111/8/JEP-2016-088). A signed informed consent was obtained from all patients.

\section{Conflict of Interest Statement}

The authors have no conflicts of interest to declare.

\section{Funding Sources}

There was no funding received for this study.

\section{Author Contributions}

Loh Chow Chin: acquisition, analysis, and interpretation of data. Haireen Kamaruddin: conception and design of the work. Mae-Lynn Catherine Bastion: revising critically for important intellectual content and final approval of the version to be published. Rahat Husain: revising critically for important intellectual content and final approval of the version to be published. Hazlita Mohd Isa: conception and design of work. Norshamsiah Md. Din: conception of design of work, interpretation of data, revising critically for important intellectual content, and final approval of the version to be published, agreement to be accountable for all aspects of the work.

\section{References}

1 Tham YC, Li X, Wong TY, Quigley HA, Aung $\mathrm{T}$, Cheng CY. Global prevalence of glaucoma and projections of glaucoma burden through 2040: a systematic review and meta-analysis. Ophthalmology. 2014 Nov;121(11):2081-90.

2 Quigley HA, Broman AT. The number of people with glaucoma worldwide in 2010 and 2020. Br J Ophthalmol. 2006 Mar 1;90(3):262-7.

3 Chew FLM, Salowi MA, Mustari Z, Husni MA, Hussein E, Adnan TH, et al. Estimates of visual impairment and its causes from the $\mathrm{Na}$ tional Eye Survey in Malaysia (NESII). PLoS One. 2018 Jun 26;13(6):e0198799.

4 Lavanya R, Wong TY, Friedman DS, Aung HT, Alfred T, Gao H, et al. Determinants of angle closure in older Singaporeans. Arch Ophthalmol. 2008 May 1;126(5):686-91.

5 Razeghinejad MR, Banifatemi M. Ocular biometry in angle closure. J Ophthalmic Vis Res. 2013 Jan;8(1):17-24.

6 George R, Paul PG, Baskaran M, Ramesh SV, Raju P, Arvind H, et al. Ocular biometry in occludable angles and angle closure glaucoma: a population-based survey. Br J Ophthalmol. 2003 Apr 1;87(4):399-402.
7 Chen YY, Chen YY, Sheu SJ, Chou P. The biometric study in different stages of primary angle-closure glaucoma. Eye. 2013 Sep;27(9): 1070-6.

8 Lan YW, Hsieh JW, Hung PT. Ocular biometry in acute and chronic angle-closure glaucoma. Ophthalmologica. 2007;221(6):38894.

9 Negrel AD, Maul E, Pokharel GP, Zhao J, Ellwein LB. Refractive error study in children: sampling and measurement methods for a multi-country survey. Am J Ophthalmol. 2000 Apr;129(4):421-6.

10 Liu X, Ye H, Zhang Q, Cai X, Yu W, Yu S, et al. Association between myopia, biometry and occludable angle: the Jiangning eye study. PLoS One. 2016 Oct 20;11(10):e0165281.

$11 \mathrm{Su}$ CW, Chen HY. Acute angle closure in the setting of high axial myopia: a case report. Am J Ophthalmol Case Rep. 2016;1:31-3.

12 Chakravarti T, Spaeth GL. The prevalence of myopia in eyes with angle closure. J Glaucoma. 2007 Oct;16(7):642-3.
13 Yong KL, Gong T, Nongpiur ME, How AC, Lee HK, Cheng L, et al. Myopia in asian subjects with primary angle closure: implications for glaucoma trends in East Asia. Ophthalmology. 2014 Aug;121(8):1566-71.

14 Barkana Y, Shihadeh W, Oliveira C, Tello C, Liebmann JM, Ritch R. Angle closure in highly myopic eyes. Ophthalmology. 2006 Feb; 113(2):247-54.

15 Department of Statistics Malaysia [Internet]. Available from: https://www.dosm.gov.my/ v1/index.php.

16 Department of Statistics Singapore [Internet]. Population Trends, 2019. 2019. Available from: https://www.singstat.gov.sg/publications/population/population-trends.

17 Foster PJ, Buhrmann R, Quigley HA, Johnson GJ. The definition and classification of glaucoma in prevalence surveys. Br J Ophthalmol. 2000;86(2):238-42.

18 Pascolini D, Mariotti SP. Global estimates of visual impairment: 2010. Br J Ophthalmol. 2012 May;96(5):614-8. 
19 Holden BA, Fricke TR, Wilson DA, Jong M, Naidoo KS, Sankaridurg P, et al. Global prevalence of myopia and high myopia and temporal trends from 2000 through 2050. Ophthalmology. 2016 May;123(5):103642.

20 Pan CW, Zheng YF, Anuar AR, Chew M, Gazzard G, Aung T, et al. Prevalence of refractive errors in a multiethnic Asian population: the Singapore epidemiology of eye disease study. Invest Ophthalmol Vis Sci. 2013 Apr 9;54(4): 2590-8.

21 Ling S, Ronald BM, Ravikanth M, Lisa B, Catherine S, Neil R, et al. The association of refractive error with glaucoma in a multiethnic population. Ophthalmology. 2016;123(1): 92-101.
22 Bonomi L, Marchini G, Marraffa M, Bernardi P, De Franco I, Perfetti S, et al. Epidemiology of angle-closure glaucoma. Prevalence, clinical types, and association with peripheral anterior chamber depth in the Egna-Neumarkt glaucoma study. Ophthalmology. 2000 May; 107(5):998-1003.

23 Dagi LR, Walton DS. Anterior axial lens subluxation, progressive myopia, and angle-closure glaucoma: recognition and treatment of atypical presentation of ectopia lentis. J AAPOS. 2006; 10(4):345-50.

24 Saxena S, Agrawal PK, Pratap VB, Nath R, Saxena RC. The predictive value of the relative lens position in primary angle-closure glaucoma. Ann Ophthalmol. 1993;25(12): 453-6.
25 Otori Y, Tomita Y, Hamamoto A, Fukui K, Usui S, Tatebayashi M. Relationship between relative lens position and appositional closure in eyes with narrow angles. Jpn J Ophthalmol. 2011;55(2):103-6.

26 Angmo D, Singh R, Chaurasia S, Yadav S, Dada T. Evaluation of anterior segment parameters with two anterior segment optical coherence tomography systems: Visante and Casia, in primary angle closure disease. Indian J Ophthalmol. 2019 Apr;67(4):500-4.

27 Moghimi S, Vahedian Z, Fakhraie G, Ghaffari $\mathrm{R}$, Eslami $\mathrm{Y}$, Jabarvand $\mathrm{M}$, et al. Ocular biometry in the subtypes of angle closure: an anterior segment optical coherence tomography study. Am J Ophthalmol. 2013 Apr;155(4): $664-73$. 